\title{
INJÚRIAS MECÂNICAS E SEUS EFEITOS NA QUALIDADE DE MAMÕES GOLDEN ${ }^{1}$
}

\author{
ANA ELISA DE GODOY², ANGELO PEDRO JACOMINO 3 , \\ ELAINE COSTA CERQUEIRA-PEREIRA ${ }^{2}$, ANITA DE SOUZA DIAS GUTIERREZ4 ${ }^{4}$, \\ CARLOS EDUARDO MORAIS VIEIRA ${ }^{5}$, LUCIMARA APARECIDA FORATO ${ }^{6}$
}

RESUMO - O objetivo do trabalho foi identificar as injúrias mecânicas que ocorrem em mamões 'Golden' e avaliar seus efeitos na qualidade dos frutos armazenados a $22^{\circ} \mathrm{C}$ e $85 \%$ UR durante 10 dias. As injúrias identificadas como abrasão, corte e amassado foram reproduzidas nos frutos. As abrasões foram provocadas com lixa grão 200, numa área de $6 \mathrm{~cm}^{2}$. Os cortes foram realizados com incisões de $30 \mathrm{~mm}$ de comprimento e $5 \mathrm{~mm}$ de profundidade. $\mathrm{O}$ amassado foi provocado pelo impacto dos frutos, que foram deixados cair de uma altura de $2 \mathrm{~m}$. Cada fruto recebeu 2 injúrias em lados opostos, na região de maior diâmetro. Mamões intactos foram utilizados como controle. A região danificada pela abrasão não desenvolveu cor amarelo-alaranjada; ocorreu escurecimento da casca, comprovado pelos menores valores de luminosidade e cromaticidade. Abrasão e impacto levaram a maior redução da firmeza da polpa e perda de massa. Imagens de ressonância magnética revelaram que frutos danificados pelas injúrias perderam sua integridade, o que foi identificado por áreas claras devido à presença de água livre. A qualidade de mamões 'Golden' é prejudicada por injúrias mecânicas, principalmente pelo impacto e pela abrasão.

Termos para Indexação: Carica papaya L., pós-colheita, impacto, abrasão, corte.

\section{MECHANICAL INJURIES AND THE EFFECTS ON THE QUALITY OF GOLDEN PAPAYA FRUITS}

\begin{abstract}
This work aimed to identify the mechanical injuries that occur in 'Golden' papaya fruits, and to evaluate the injuries effects on the quality of the fruits at early ripening stage and storage at $22^{\circ} \mathrm{C}$ and $85 \%$ RH for 10 days. The mechanical injuries identified were abrasion, cuts and bruises. Abrasion was caused by 200 mesh sandpaper in a $6 \mathrm{~cm}^{2}$ of peel surface area. Cut injury was obtained by cutting fruits at $30 \mathrm{~mm}$ length and $5 \mathrm{~mm}$ depth. Bruises were produced in the papayas by impact, which were dropped from $2 \mathrm{~m}$ height onto a hard surface. Each fruit were injured twice in the opposite sides at the widest diameter region. Intact fruits were considered as control. Injured areas by abrasion did not develop the typical yellow color. The luminosity and chroma values were lower in injured areas. Abrasion and impact injuries were responsible for flesh firmness decrease and higher water loss. Magnetic resonance images showed that injured papaya fruits lost their integrity. In the injured areas were visualized clear region due to free water content. The quality of 'Golden' papaya fruits is affect by mechanical injuries, mainly due to the impact and the abrasion injuries.

Index terms: Carica papaya L., postharvest, impact, abrasion, cut.
\end{abstract}

\footnotetext{
'(Trabalho 141-09). Recebido em: 05-06-2009. Aceito para publicação em: 06-04-2010.

${ }^{2}$ Eng $^{\circ}$.Agr ${ }^{\circ}$., Doutoranda, Escola Superior de Agricultura "Luiz de Queiroz”, Dep. De Produção Vegetal, Caixa Postal 9, CEP 13418900 Piracicaba-SP. Email: aelisagodoy@yahoo.com.br; eccerque@esalq.usp.br

${ }^{3}$ Eng $^{\circ}$.Agr ${ }^{\circ}$., Professor Doutor Escola Superior de Agricultura "Luiz de Queiroz", Dep. De Produção Vegetal, Caixa Postal 9, CEP 13418-900 Piracicaba-SP. Email: jacomino@esalq.usp.br

${ }^{4}$ Eng $^{\text {}}$.Agr ${ }^{\circ}$., Chefe do Seção do Centro de Qualidade Hortigrangeira da CEAGESP, Companhia de Entrepostos e Armazéns Gerais de São Paulo - CEAGESP - CEP 05316-900, São Paulo-SP. Email: adias@ceagesp.gov.br

${ }^{5}$ Bacharel em Química, Instituto de Química de São Paulo, USP. Avenida Trabalhador São-Carlense, 400, Caixa Postal 780, CEP 13560-970, São Carlos-SP. Email: cmvieira@gmail.com

${ }^{6}$ Pesquisadora Embrapa Instrumentação Agropecuária, CEP 13560-970, São Carlos, SP. Email: lucimara@cnpdia.embrapa.br
} 


\section{INTRODUÇÃO}

O Brasil é o maior produtor mundial de mamão, com produção de aproximadamente 1,6 milhão $t$ ano ${ }^{-1}$ e apresenta grande potencial de crescimento, sendo praticamente toda a produção destinada ao mercado in natura e, desse total, 38 mil toneladas são exportadas (Agrianual, 2008).

O mamão apresenta vida pós-colheita relativamente curta e completa o seu amadurecimento em aproximadamente uma semana sob condição ambiente. No entanto, vários fatores de pré e póscolheita podem reduzir sua vida de prateleira. Esses fatores podem manifestar-se nos frutos isoladamente ou em conjunto, proporcionando perdas quantitativas e qualitativas nas diferentes fases da comercialização (COSTA;BALBINO, 2002; ZAMPERLINI et al., 2007). Além de se tratar de uma fruta altamente perecível, o manuseio adotado na sua pós-colheita é agressivo e resulta em muitas injúrias mecânicas. As suas consequências podem ser causa primária de perdas nas etapas subsequentes, pois aceleram a perda de água, levam ao acréscimo na atividade respiratória e diminuição da matéria seca dos frutos (WILLS et al., 1998).

Os danos mecânicos são definidos como deformações plásticas, rupturas superficiais e destruição dos tecidos vegetais, provocados por forças externas. Adicionalmente, levam a modificações físicas e alterações fisiológicas, químicas e bioquímicas que modificam a cor, o aroma, o sabor e a textura dos vegetais (MOHSENIN, 1986). Existem informações de que as injúrias mecânicas causam danos irreparáveis em frutas como goiabas (MATTIUZ et al., 2001a,b) limões (DURIGAN et al., 2005) e pêssegos (KASAT et al., 2007). Desse modo, o objetivo do trabalho foi identificar as injúrias mecânicas que ocorrem em mamões 'Golden' e avaliar os seus efeitos na qualidade dos frutos.

\section{MATERIAL E MÉTODOS}

Foi realizado um estudo de caso com base em mamões 'Golden' provenientes das regiões produtoras do Espírito Santo e da Bahia. Os frutos foram acondicionados em embalagens de madeira, transportados em caminhão de carga seca lonada e não paletizada e analisados entre abril de 2007 e maio de 2008, para identificar e caracterizar as injúrias mecânicas que mais ocorrem na cadeia de comercialização do mamão, na Companhia de Entrepostos e Armazéns Gerais de São Paulo - CEAGESP. Sessenta e oito caixas de mamões foram analisadas de 11 atacadistas, aleatoriamente, totalizando 1.064 frutos, dos quais foram contabilizadas e caracterizadas as injúrias mecânicas. Foi identificada a região do fruto na qual ocorreu o dano e caracterizadas em mediana, peduncular e estilar, selecionando-se as três injúrias predominantes em mamões para reproduzilas em laboratório.

As injúrias mecânicas identificadas como sendo de maior ocorrência (abrasão, corte e amassado) foram reproduzidas em mamões 'Golden' provenientes do município de Linhares-ES. Foram utilizados frutos acondicionados em embalagens de papelão no estádio 1 de maturação (até $15 \%$ da superfície da casca com coloração amarela), os quais foram transportados sob refrigeração da região produtora até a CEASA/Campinas-SP. Os frutos foram recebidos e transportados ao Laboratório de PósColheita de Produtos Hortícolas da ESALQ/USP, em Piracicaba-SP, onde foram selecionados frutos sem defeitos e submetidos às injúrias mecânicas. A injúria de abrasão foi provocada com lixa grão 200 . Fixou-se no fruto uma etiqueta adesiva com orifício central de $6 \mathrm{~cm}^{2}$, sobre a qual a lixa foi friccionada manualmente, uma única vez, para provocar a injúria na área delimitada pelo adesivo. Na injúria por corte, foram realizadas incisões de $30 \mathrm{~mm}$ de comprimento e $5 \mathrm{~mm}$ de profundidade, utilizando uma lâmina fixada num suporte de madeira que suportava uma força de $7,5 \mathrm{~kg}$, à qual os frutos ficavam submetidos por 15 minutos para que ocorresse o corte. A injúria de amassado foi provocada através do impacto dos frutos. Um mamão por vez foi colocado em saco de malha fina e lisa, no tamanho de $15 \mathrm{~cm}$ de comprimento e $10 \mathrm{~cm}$ de largura, para evitar a rotação do fruto durante a queda. Os frutos foram deixados cair de uma altura de $2 \mathrm{~m}$, numa caixa de madeira com fundo plano, maciço e rígido. Cada fruto sofreu duas injúrias em lados opostos, na região de maior diâmetro, sendo que cada fruto recebeu apenas um tipo de injúria. As áreas danificadas foram demarcadas, e os frutos armazenados a $22 \pm 1^{\circ} \mathrm{C}$ e $85 \pm 5 \%$ UR, durante 10 dias. Frutos intactos foram utilizados como controle.

As variáveis determinadas foram: a) ângulo de cor $\left({ }^{\circ} \mathrm{h}\right)$, luminosidade e cromaticidade, utilizando colorímetro (Minolta CR-300, Osaka, Japão). Realizaram-se quatro leituras por fruto, em pontos equidistantes, na região equatorial, sendo duas nas áreas com injurias (uma sobre cada injúria) e outras duas nas áreas sem injúrias; b) firmeza da polpa foi determinada com penetrômetro digital (53200-Samar, Tr Turoni, Forli, Itália) com ponteira de $8 \mathrm{~mm}$ de diâmetro. Realizaram-se quatro leituras por fruto, em pontos equidistantes, na região equatorial, após a retirada da casca, sendo duas leituras nas áreas com 
injurias (uma sobre cada injúria) e outras duas nas áreas sem injúrias. Os resultados foram expressos em Newton $(\mathrm{N})$; c) teor de sólidos solúveis, avaliado em refratômetro digital (Atago PR-101, Atago Co Ltda., Tókio, Japão); d) acidez titulável e teor de ácido ascórbico foram determinados de acordo com a metodologia descrita por Carvalho et al. (1990); e) perda de massa foi determinada pela diferença entre a massa inicial e a massa final da amostra em balança semianalítica. Os resultados foram expressos em porcentagem.

Mamões foram analisados em tomógrafo de ressonância magnética nuclear Varian, modelo INOVA 2 Tesla, que opera na frequência de 85,53 MHz para núcleos de hidrogênio, na Embrapa Instrumentação Agropecuária em São Carlos-SP. Para aquisição das imagens, foi utilizada a sequência de spin-eco, usando um tempo de eco de $60 \mathrm{~ms}$, tempo de repetição de 2 segundos (imagens ponderadas em $\mathrm{T}_{2}$ ) e número de médias de aquisições igual a 4 $(\mathrm{nt}=4)$. As imagens geradas em matrizes de 256x256 pixels foram captadas quatro dias após a reprodução das injúrias mecânicas. Foram realizadas imagens do tipo transversal para as injúrias de impacto, corte, abrasão e fruto sem injúria mecânica.

O delineamento experimental adotado foi o inteiramente casualizado, em esquema fatorial, composto por três fatores (tipo de injúria, região com ou sem lesão e dias de armazenamento após a injúria) para as variáveis de cor e firmeza e por dois fatores (tipo de injúria e dias de armazenamento após a injúria) para as demais variáveis analisadas. Foram utilizadas oito repetições de um fruto para as análises químicas e 20 repetições de um fruto para a análise de perda de massa. A perda de massa fresca foi analisada por regressão linear. Os resultados obtidos foram submetidos à análise de variância, e as médias, comparadas pelo teste de Tukey (5\%).

Os resultados das porcentagens de frutos com danos mecânicos foram transformados para a análise estatística em arco-seno $\sqrt{x / 100}$. Os demais dados não sofreram transformações.

\section{RESULTADOS E DISCUSSÃO}

As principais injúrias mecânicas encontradas nos mamões foram abrasões, cortes e amassados, e a maior porcentagem dessas injúrias foi verificada na região mediana dos frutos (Figura 1). A alta ocorrência de abrasões foi devida, provavelmente, ao manejo e ao uso de embalagem de superfície abrasiva, como as de madeira. Observou-se a formação de lesões com extravasamento de látex, e posteriormente a região do dano ficou enegrecida. A exsudação de látex ocorre devido à ruptura dos vasos laticíferos localizados abaixo da epiderme (QUINTANA;PAULL, 1993). As abrasões ocorrem quando há movimento dos frutos no interior da embalagem durante algum tipo de movimento, resultando em lesões que podem variar de marcas superficiais de abrasão até a remoção substancial de tecido (SOUZA et al., 2003). Injúrias mecânicas provocadas por abrasões e impactos foram caracterizadas como de maior ocorrência em mamões posicionados nas laterais das embalagens por Quintana e Paull (1993).

As injúrias causadas por cortes, provavelmente, aconteceram devido à pressão sobre o fruto contra uma superfície desigual, como as quinas das embalagens. Segundo Mattiuz e Durigan (2001a), a injúria por corte é, geralmente, atribuída à colisão da superfície do fruto contra uma muito menor que a primeira, ocasionando a ruptura da epiderme, ou pela imposição de uma pressão sobre o fruto contra superfícies também desiguais, como as arestas de uma embalagem.

As injúrias do tipo amassado foram ocasionadas, possivelmente, pelo impacto sofrido pelos frutos contra uma superfície sólida, durante os processos da colheita e pós-colheita. Segundo Quintana e Paull (1993), os danos causados por impactos provocam o amassamento, ocasionados pelo choque do produto com superfícies rígidas, individualmente ou dentro de embalagens, causando danos externos com formação de lesões aquosas translúcidas e amolecidas.

$\mathrm{O}$ ângulo de cor $\left({ }^{\circ} \mathrm{h}\right)$, a luminosidade e a cromaticidade foram afetados pela abrasão $(\mathrm{P}<0,05)$ (Figura 2). A região injuriada do fruto não desenvolveu a cor amarelo-alaranjada, evidenciada pelo maior valor do ângulo de cor $\left(93,16^{\circ}\right)$, enquanto a região não injuriada atingiu valor médio de $78,66^{\circ}$. Além disso, ocorreu escurecimento da casca na região da abrasão, já no $2^{\circ}$ dia de armazenamento, o que é comprovado pelos menores valores de luminosidade $(58,71)$ e cromaticidade $(37,13)$. Considerando as regiões não injuriadas do fruto, os valores foram de 71,21 para luminosidade e 51,02 para cromaticidade. Quando a célula é rompida, devido à magnitude da força empregada, ocorre o extravasamento do líquido celular e sua consequente exposição à ação enzimática, o que promove a oxidação de compostos fenólicos a quinonas, levando ao aparecimento de pigmentos de coloração marrom (RADI et al., 1997).

O corte também alterou a luminosidade e a cromaticidade da casca, considerando as regiões injuriadas e as não injuriadas do fruto durante o armazenamento $(\mathrm{P}<0,05)$ (Figura 2). A luminosidade $\mathrm{e}$ a cromaticidade indicaram que a região com o corte tornou-se mais escura, e a intensidade de pigmentos 
foi menor do que na região não injuriada do fruto. Em goiabas 'Paluma' e 'Pedro Sato', a área injuriada também se apresentou mais escura nos frutos submetidos ao corte (MATTIUZ; DURIGAN, 2001b).

Dentre as injúrias, a provocada pelo impacto levou os mamões ao amarelecimento mais rápido, indicada pela redução do ângulo de cor, aumento na luminosidade e cromaticidade (Figura 2). De acordo com Mattiuz e Durigan (2001b), o aumento da luminosidade, associado ao aumento na cromaticidade e à diminuição do ângulo de cor, revela que houve perda da cor verde, fazendo com que os frutos adquirissem tonalidade amarelada. Não houve diferença de coloração da casca entre a região com e sem injúria $(\mathrm{P} \geq 0,05)$ para mamões submetidos ao impacto.

A firmeza da polpa foi menor nos frutos submetidos às injúrias mecânicas. As injúrias causadas pela abrasão e pelo impacto foram as que mais reduziram a firmeza dos frutos $(\mathrm{P}<0,05)$ (Figura 3). A abrasão também promoveu redução na firmeza de bananas (LLADÓ; DOMÍNGUEZ, 1998) e o impacto foi responsável pela perda de firmeza em pêssegos (KASAT et al., 2007). As injúrias mecânicas causam a perda de firmeza devido à ruptura celular e atividade enzimática, principalmente pelas enzimas que degradam a parede celular, como a poligalacturonase, pectinametilesterase e celulase (MILLER et al., 1987).

Mamões submetidos à abrasão e ao corte apresentaram baixa firmeza, na região danificada, já no $2^{\circ}$ dia após a reprodução das injúrias $(\mathrm{P}<0,05)$. A diferença nos valores de firmeza entre as regiões danificadas e as que permaneceram intactas, dos frutos submetidos à abrasão e ao corte, foi observada apenas no início do armazenamento, uma vez que a região não danificada apresentou perda de firmeza a partir do $4^{\circ}$ dia de armazenamento. Mamões submetidos ao impacto não apresentaram diferenças na firmeza entre as áreas com injúrias e intactas do fruto durante o armazenamento $(P \geq 0,05)$, provavelmente, pela magnitude do impacto causado no fruto como um todo. Mamões intactos mantiveram a firmeza da polpa elevada até o $6^{\circ}$ dia de armazenamento (Figura 3).

As injúrias provocaram aumento na perda de massa fresca durante o armazenamento. Dentre as injúrias, o impacto e a abrasão levaram à maior perda de massa fresca, correspondendo a 19 e $16 \%$ a mais que os frutos-controle, respectivamente $(\mathrm{P}<0,05)$ (Tabela 1). Comportamento semelhante foi observado para pêssegos (KASAT et al., 2007), que sofreram injúrias mecânicas de impacto, e mamões (BRAGA, 2004), que sofreram injúrias por abrasões. As injúrias mecânicas muitas vezes danificam as barreiras que evitam a perda de água, a qual é uma das causas principais da perda de qualidade pós-colheita, e resulta na redução imediata da massa do fruto (ALAYUNT et al., 1998).

O teor de ácido ascórbico foi maior nos mamões que receberam a injúria mecânica de abrasão $(\mathrm{P}<0,05)$ (Tabela 2). Esse resultado, provavelmente, pode ser corroborado pelo maior teor de sólidos solúveis nos frutos do mesmo tratamento. BarataSoares et al. (2004) observaram a biossíntese do ácido ascórbico durante o amadurecimento de mamões, indicando aumento do seu nível, quando açúcares como L-galactono-1,4-lactono foram infiltrados em amostras de mamão, sendo esse açúcar caracterizado como precursor na biossíntese do ácido ascórbico, verificado na rota descrita por Wheeler et al. (1998). A degradação de polissacarídeos da parede celular com o amadurecimento, possivelmente, resulta em um aumento da galactose, que é um dos precursores da biossíntese do ácido ascórbico (WHEELER et al., 1998; SMIRNOFF et al., 2001). A baixa firmeza da polpa dos frutos submetidos à abrasão, possivelmente, devido à degradação da parede celular, fornece substratos para a síntese de ácido ascórbico, podendo explicar o fato dos teores serem maiores. Houve aumento no teor de ácido ascórbico durante o armazenamento. Em mamão, tem sido registrado aumento do teor deste nutriente durante o amadurecimento (BARATA-SOARES et al.; 2004; BRON et al., 2006).

$\mathrm{O}$ teor de sólidos solúveis nos frutos com abrasão foi maior $(\mathrm{P}<0,05)$ do que nos mamões injuriados pelo corte e dos frutos-controle (Tabela 2). Esse resultado se deve, provavelmente, à menor atividade respiratória destes frutos. Durante o armazenamento, houve redução do teor de sólidos solúveis para todos os tratamentos. A redução do conteúdo de açúcares redutores e sólidos solúveis totais em frutos injuriados pode estar relacionada à utilização destes compostos como substrato respiratório (MATTIUZ; DURIGAN, 2001a). Giannoni et al. (1996) observaram, em pêssego, aumento do teor de sólidos solúveis, indicando que este aumento foi devido à perda de água pelos frutos durante o armazenamento. Esse fato pode estar correlacionado com os teores de sólidos solúveis dos frutos submetidos à abrasão e ao impacto, já que estas injúrias também promoveram maior perda de massa dos frutos.

Os frutos com injúrias apresentaram maior acidez que os frutos-controle durante o armazenamento $(\mathrm{P}<0,05)$. Esse resultado pode ser atribuído à formação do ácido galacturônico no processo de degradação da parede celular, processo que ocorre durante o amadurecimento do mamão (COSTA; 
BALBINO, 2002), e que, possivelmente, foi acelerado pelas injúrias mecânicas. No início e no final do período de armazenamento, os níveis de acidez foram maiores. Talvez pelo fato de que, inicialmente, os frutos estavam mais verdes e, no final do armazenamento, ocorreu o processo de solubilização das pectinas, o que tornou o meio mais ácido. Os valores mais baixos de acidez, entre o $4^{\circ}$ e o $8^{\circ}$ dia, podem ter sido decorrentes do processo respiratório ou de sua conversão em açúcares.

A Figura 4 mostra imagens obtidas pela tomografia de ressonância magnética de mamões submetidos e não submetidos às injúrias mecânicas. Neste tipo de imagem, os núcleos de hidrogênios com maior mobilidade $\left(T_{2}\right.$ longo) aparecem como porções claras, ao passo que aqueles com menor mobilidade ( $T_{2}$ curto), em regiões mais escuras. Desse modo, a baixa densidade de núcleos de hidrogênios com baixa mobilidade $\left(T_{2}\right.$ curto) gera regiões acinzentadas. Os frutos submetidos às injúrias mecânicas apresentaram regiões com tonalidade mais clara (Figura 4-b, c, d) e contrasta com a imagem do fruto sem injúria mecânica (Figura 4-a), pela área com coloração acinzentada. Essas regiões com áreas claras mais intensas podem ser explicadas como provenientes de condição de distúrbio, sob as quais as membranas celulares são afetadas e perdem sua integridade, aumentando o conteúdo de água livre e as áreas cinza-escuro indicam baixa densidade de núcleos de hidrogênio com mobilidade, devido à pouca disponibilidade de água livre, que pode promover espaços contendo gases, que aparecem como regiões escuras (LAMMERTYN et al., 2003).

A coloração mais acinzentada na região do lóculo da Figura 4-a, provavelmente, ocorreu pela presença de pouca água livre ao redor da semente, sugerindo que estas estão mais unidas. Lima et al. (2004) observaram coloração cinza-escura em melões 'Galia' tratados com 1-MCP, indicando sementes mais presas, uma vez que havia pouca água livre ao seu redor.

É possível verificar, na Figura 4-b, uma depressão na epiderme do fruto formada pelo corte. Mattiuz et al. (2002) também observaram deformações na formato de goiabas 'Paluma' e 'Pedro Sato' ocasionada pelo corte, bem como a ocorrência de áreas mais claras nas regiões próximas ao local da injúria. A injúria por abrasão (Figura 4-c) causou alteração no formato do fruto, deixando a região danificada com aspecto enrugado, provavelmente, devido à perda acentuada de massa fresca, já que injúrias por abrasão expõem os tecidos internos do fruto, pois remove o sistema dérmico, que tem a função de regular a perda de água. A injúria causada pelo impacto (Figura 4-d) provocou o colapso interno, observado pela coloração esbranquiçada na região interna do fruto, mais próxima à região locular. De acordo com Mattiuz et al. (2002), o colapso interno leva à perda da integridade celular e à consequente liquefação dos tecidos placentários, com extravasamento celular. O mesmo resultado foi observado por Mattiuz et al. (2002) em goiabas 'Paluma' e 'Pedro Sato'.

TABELA 1 - Equações representativas da perda de massa (\%) $(n=20)$ de mamões 'Golden' submetidos a diferentes danos mecânicos e armazenados a $22 \pm 1^{\circ} \mathrm{C}$ e $85 \pm 5 \%$ UR durante 7 dias.

\begin{tabular}{cccc}
\hline Tratamentos & $\mathrm{y}=\mathrm{a}+\mathrm{bx}$ & $\mathrm{r}^{2}$ & Média \\
\hline Controle & $\mathrm{y}=1,3039+0,6339$ & 0,9985 & $4,07 \mathrm{c}$ \\
Impacto & $\mathrm{y}=1,6980+0,8482$ & 0,9990 & $5,09 \mathrm{a}$ \\
Corte & $\mathrm{y}=1,3941+0,7526$ & 0,9989 & $4,40 \mathrm{~b}$ \\
Abrasão & $\mathrm{y}=1,5889+0,8203$ & 0,9989 & $4,87 \mathrm{a}$ \\
\hline
\end{tabular}

$\mathrm{y}=$ massa fresca $(\mathrm{g}) ; \mathrm{x}=$ tempo de armazenamento (dia)

Médias seguidas de mesma letra não diferem entre si, pelo teste de Tukey, a 5\% de probabilidade 
TABELA 2 - Características de qualidade de mamões 'Golden' submetidos a injúrias mecânicas e armazenados a $22^{\circ} \mathrm{C}$ e $85 \pm 5 \%$ durante 10 dias.

\begin{tabular}{cccc}
\hline Injúrias mecânicas & $\begin{array}{c}\text { Ácido ascórbico } \\
\left(\mathrm{mg} 100 \mathrm{~g}^{-1}\right)\end{array}$ & $\begin{array}{c}\text { Sólidos solúveis } \\
\left({ }^{\circ} \text { Brix }\right)\end{array}$ & $\begin{array}{c}\text { Acidez titulável } \\
(\% \text { ácido cítrico })\end{array}$ \\
\hline Impacto & $83,163 \mathrm{~b}^{1}$ & $12,066 \mathrm{ab}$ & $0,0718 \mathrm{a}$ \\
Corte & $82,005 \mathrm{~b}$ & $11,835 \mathrm{~b}$ & $0,0734 \mathrm{a}$ \\
Abrasão & $92,594 \mathrm{a}$ & $12,415 \mathrm{a}$ & $0,0716 \mathrm{a}$ \\
Controle & $83,757 \mathrm{~b}$ & $11,925 \mathrm{~b}$ & $0,0633 \mathrm{~b}$ \\
\hline DMS & 5,718 & 0,376 & 0,064 \\
\hline Teste F & $987,838^{*}$ & $2,599^{*}$ & $0,081^{*}$ \\
\hline Dias & & & \\
\hline 2 & $79,308 \mathrm{c}$ & $13,066 \mathrm{a}$ & $0,0778 \mathrm{a}$ \\
4 & $84,022 \mathrm{bc}$ & $12,052 \mathrm{~b}$ & $0,0629 \mathrm{c}$ \\
6 & $83,435 \mathrm{bc}$ & $11,933 \mathrm{bc}$ & $0,0701 \mathrm{bc}$ \\
8 & $88,465 \mathrm{ab}$ & $11,717 \mathrm{bc}$ & $0,0647 \mathrm{c}$ \\
10 & $91,612 \mathrm{a}$ & $11,534 \mathrm{c}$ & $0,0742 \mathrm{ab}$ \\
\hline DMS & 6,794 & 0,447 & 0,076 \\
\hline Teste F & $726,845^{*}$ & $11,371^{*}$ & $0,126^{*}$ \\
\hline CV $(\%)$ & 11,52 & 5,37 & 15,69 \\
\hline
\end{tabular}

${ }^{1}$ Médias seguidas de mesma letra, na coluna, não diferem entre si, pelo teste de Tukey, a $5 \%$ de probabilidade

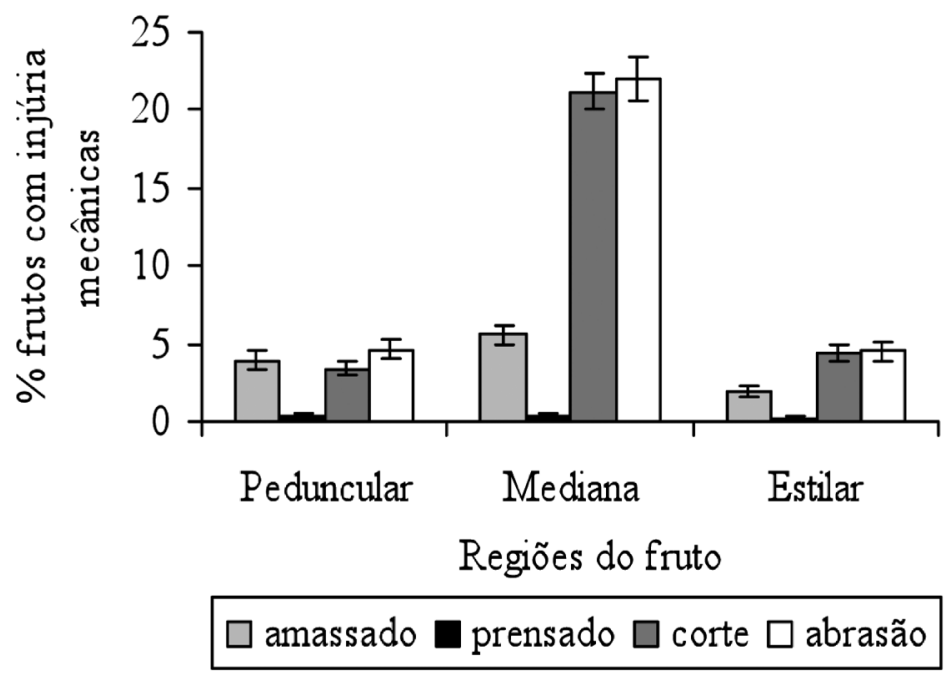

FIGURA 1 - Danos mecânicos encontrados na pós-colheita de mamão ‘Golden’ em embalagem de madeira. Peduncular, mediana e estilar correspondem às regiões do fruto onde foram identificados os danos. 

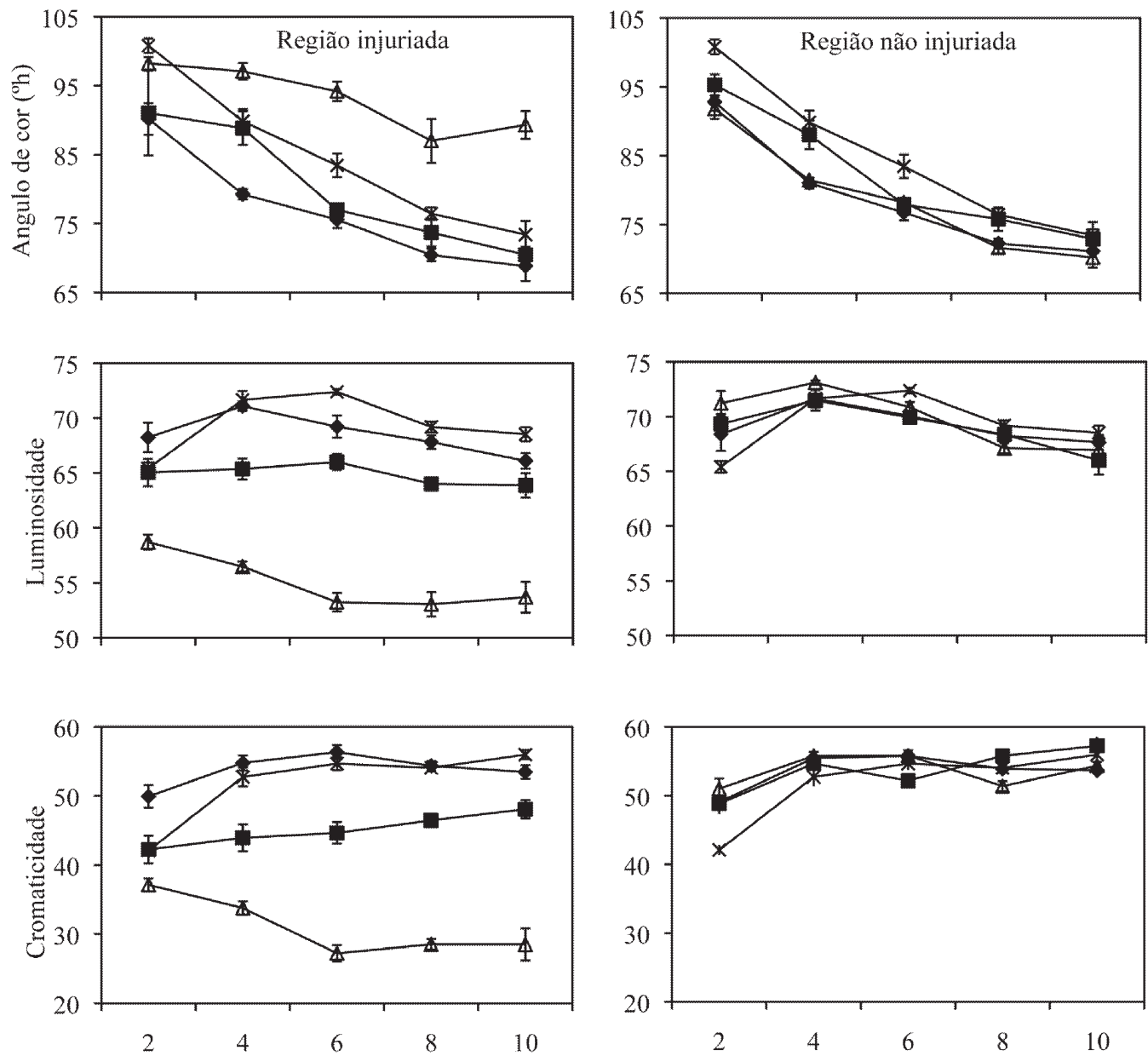

Dias de armazenamento a $22^{\circ} \mathrm{C}$

Dias de armazenamento a $22^{\circ} \mathrm{C}$

Corte $\triangle$ Abrasão $*$ Controle

FIGURA 2 - Ângulo de cor $\left({ }^{\circ} \mathrm{h}\right)$, luminosidade e cromaticidade da casca de mamões 'Golden' submetidos a danos mecânicos e armazenados a $22 \pm 1^{\circ} \mathrm{C}$ e $85 \pm 5 \%$ UR durante 10 dias. As barras verticais representam o erro $(\mathrm{n}=8)$. 


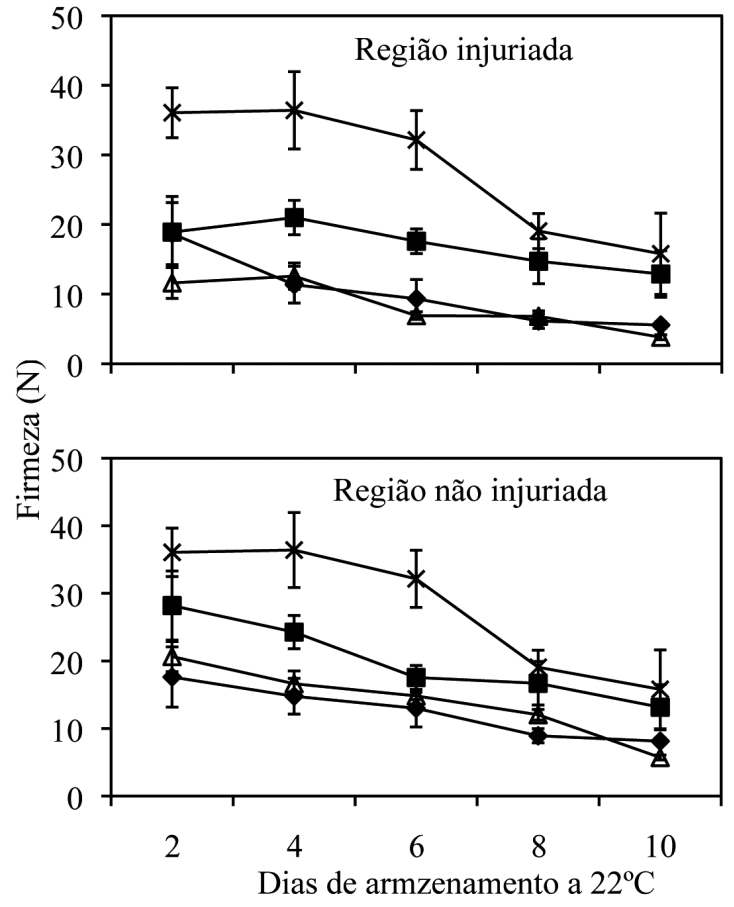

$\rightarrow$ Impacto $\rightarrow$-Corte $\triangle$ Abrasão $\rightarrow$ Controle

FIGURA 3 - Firmeza (N) de mamões 'Golden' submetidos a danos mecânicos e armazenados a $22 \pm 1{ }^{\circ} \mathrm{C}$ e $85 \pm 5 \%$ UR. As barras verticais representam o erro $(n=8)$.

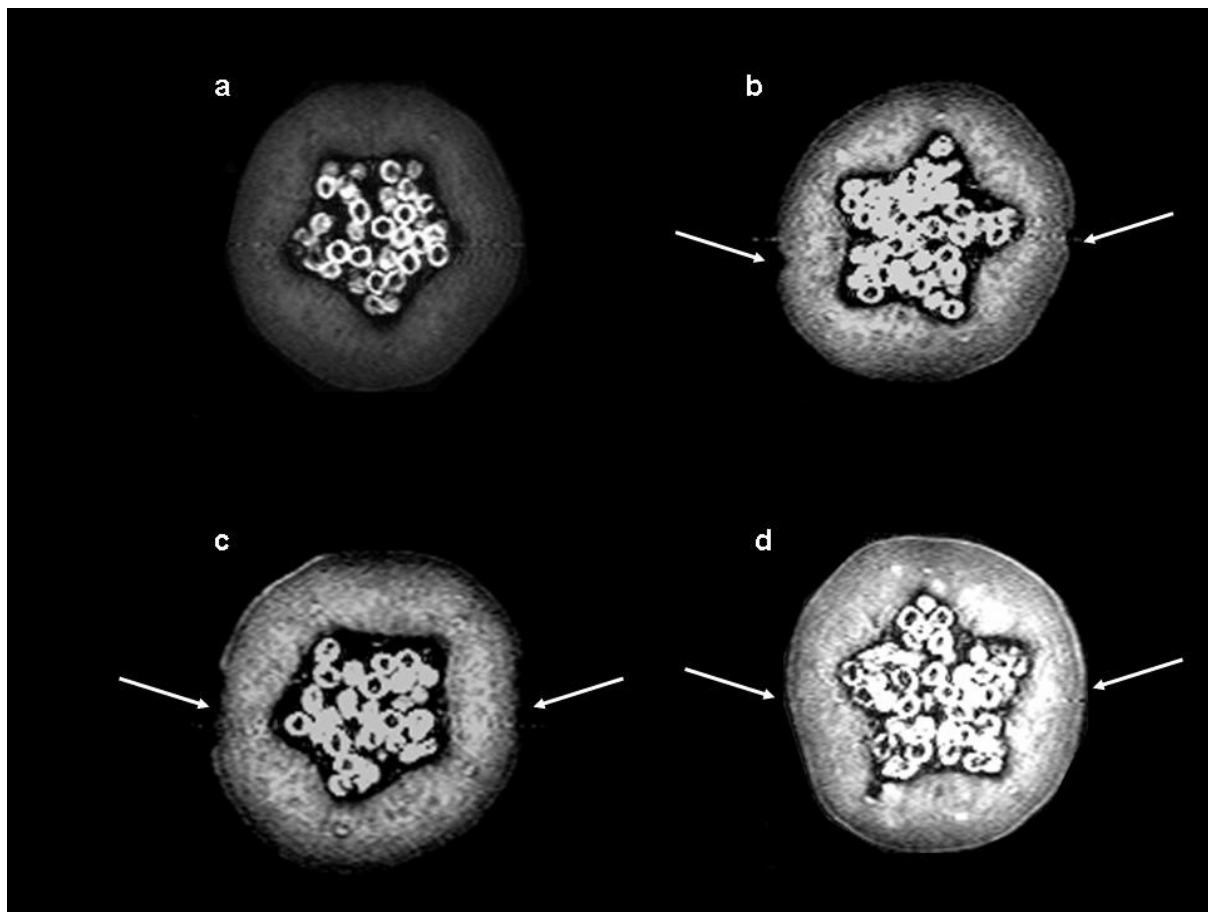

FIGURA 4 - Imagens do tipo transversal para as injúrias de impacto, corte, abrasão e fruto intacto obtidas por tomografia de ressonância magnética nuclear, ponderadas em $\mathrm{T}_{2}$, para mamões 'Golden'

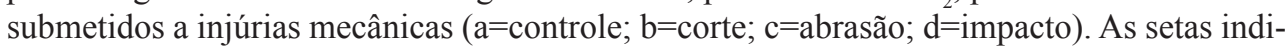
cam o local da injúria. 


\section{CONCLUSÃO}

As principais injúrias mecânicas identificadas em mamões ‘Golden' são abrasão, corte e amassado, sendo que a maior porcentagem dessas injúrias é verificada na região mediana dos frutos. Essas injúrias são responsáveis por perdas significativas na qualidade dos mamões, e as injúrias de impacto e de abrasão são as que mais contribuem para a perda de qualidade, acelerando mais rapidamente o amadurecimento dos frutos, além da maior perda de firmeza e de massa fresca. A abrasão, por sua vez, afeta a região injuriada, principalmente quanto à coloração, pois a região com a injúria fica escura, e o impacto promove amarelecimento mais rápido dos frutos.

\section{AGRADECIMENTO}

À Fundação de Amparo à Pesquisa do Estado de São Paulo/Fapesp, pelas bolsas de estudos concedidas às alunas de pós-graduação (Proc. $n^{\circ}$ 06/05929-8 e 06/04260-3).

\section{REFERÊNCIAS}

AGRIANUAL 2008: anuário estatístico da agricultura brasileira. São Paulo: FNP Consultoria e Comércio, 2007. 504 p.

ALAYUNT, F.N.; CAKMAK, B.; CAN, H.Z.; AKSOY U. Vibration damage trial on some fig cultivars. Acta Horticulturae, Wageningen, v.480, p.305-310, 1998.

BARATA-SOARES, A.D.; GÓMEZ, M.L.P.A.; MESQUITA, C.H.; LAJOLO, F.M. Ascorbic acid biosynthesis: a precursor study on plants. Brazilian Journal of Plant Physiology, Londrina, v.16, p.147154, 2004.

BRAGA, L. R. Características químicas e físicas de mamões do grupo 'Solo' submetidos a diferentes injúrias mecânicas. 2004. 46 f. Dissertação (Mestrado em Fitotecnia) - Universidade Federal de Viçosa, Viçosa, MG, 2004.

BRON, I.U.; JACOMINO, A.P.; PINHEIRO, A. L. Influence of ripening stage on physical and chemical attributes of 'Golden' papaya fruit treated with 1-Methylcyclopropene. Bragantia, Campinas, v.65, p.553-558, 2006.
CARVALHO, P.R.N.; MORAES, R.M.M. Análises químicas de alimentos. Campinas: ITAL, 1990. $121 \mathrm{p}$.

COSTA, A. F. S.; BALBINO, J. M. S. Características da fruta para exportação e normas de qualidade. In: FOLEGATTI, M. I. S.; MATSUURA, F. C. A. U. (Ed.). Mamão: pós-colheita. Brasília-DF: Embrapa Informação Tecnológica, 2002. p.12-18. (Série Frutas do Brasil, 21).

DURIGAN, M.F.B.; MATTIUZ, B.H.; DURIGAN, J.F. Injúrias mecânicas na qualidade pós-colheita de lima ácida 'Tahiti' armazenada sob condição ambiente. Revista Brasileira de Fruticultura, Jaboticabal, v.27, n.3, p.369-372, 2005.

GIANNONI, J.A.; LIMA, L.C.; CHITARRA, M.I.F.; VILAS BOAS, E.V. Armazenamento de pêssegos 'Premier' sob refrigeração e atmosfera modificada. In: CONGRESSO BRASILEIRO DE FRUTICULTURA, 14., 1996, Curitiba. Resumos... Londrina: SBF, 1996.

KASAT, G.F.; MATTIUZ, B.H.; OKUSHIRO, O.; BIANCO, M.S.; MORGADO, C.M.A.; JUNIOR, L.C.C. Injúrias mecânicas e seus efeitos em pêssegos 'Aurora-1'. Revista Brasileira de Fruticultura, Jaboticabal,v.29, p.318-322, 2007.

LAMMERTYN, J.; DRESSELAERS, T.; VAN HECKE, P.; JANCSÓK, P.; WEVERS, M.; NICOLAÝ, B.M. Analysis of the time course of core breakdown in 'Conference' pears by means of MRI and X-ray CT. Postharvest Biology and Technology, Amsterdam, v.29, p.19-28, 2003.

LIMA, M.A.C.; ALVES, R.E.; BISCEGLI, C.I.; FILGUEIRAS, H.A.C.; COCOZZA, F.M. Conservação pós-colheita de melões Galia 'Solar King' tratados com 1-metilciclopropreno. Horticultura Brasileira, Brasília, v.22, p.121-126, 2004.

LLADÓ, J.D.S.; DOMINGUEZ, A.M. The effects of peel abrasion on the postharvest physiology and commercial life of banana fruits. In: Proceedings of the first international symposium on banana in the subtropics. Acta Horticulturae, The Hague, n.490, p.547-553, 1998.

CARVALHO, C.R.L.; MANTOVANI, D.M.B.; 
MATTIUZ, B.H.; BISCEGLI, C.I.; DURIGAN, J.F. Aplicações da tomografia de ressonância magnética nuclear como método não destrutivo para avaliar os efeitos de injúrias mecânicas em goiabas 'Paluma' e 'Pedro Sato'. Revista Brasileira de Fruticultura, Jaboticabal, v.24, p.641-643, 2002.

MATTIUZ, B.H.; DURIGAN, J.F. Efeito de injúrias mecânicas na firmeza e coloração de goiabas das cultivares Paluma e Pedro Sato. Revista Brasileira de Fruticultura, Jaboticabal, v.23, p.277-281, 2001 b.

MATTIUZ, B.H.; DURIGAN, J.F. Efeito de injúrias mecânicas no processo respiratório e nos parâmetros químicos de goiabas 'Paluma' e 'Pedro Sato'. Revista Brasileira de Fruticultura, Jaboticabal, v.23, p.282-287. 2001a.

MILLER, A.R.; DALMASSO, J.P.; KRETCHMAN, D.W. Mechanical stress, storage time, and temperature influence cell wall-degrading enzymes, firmness, and ethylene production by cucumbers. Journal of the American Society for Horticultural Science, Alexandria, v.112, p.666-671, 1987.

MOHSENIN, N.N. Physical properties of plant and animal materials: structure, physical characteristics and mechanical properties. 2, ed.,New York: Gordon and Breach, 1986.891p.

QUINTANA, M.E.G.; PAULL, R.E. Mechanical injury during postharvest of 'Solo' papaya fruit. Journal of the American Society for Horticultural Science, Alexandria, v.118, p.618-622.1993.
RADI, M.; MAHROUZ, M.; JAOUAD, A. Phenolic composition, browning susceptibility, and carotenoid content of several apricot cultivars at maturity. HortScience, Alexandria, v.32, p.1087-1091, 1997.

SMIRNOFF, N.; CONKLIN, P.; LOEWUS, F.A. Biosynthesis of ascorbic acid in plants: a renaissance. Annual Review of Plant Physiology and Plant Molecular Biology, Palo Alto, v.52, p.437-467, 2001.

SOUZA, R.M.; HENZ, G.P.; PEIXOTO, J.R. Incidência de injúrias mecânicas em raízes de mandioquinha-salsa na cadeia de pós-colheita. Horticultura Brasileira, Brasília, v.21, p.712$718,2003$.

WHEELER, G.L.; JONES, M.A.; SMIRNOFF, N. The biosynthetic pathway of vitamin $\mathrm{C}$ in higher plants. Nature, London, v.393, p.365-369, 1998.

WILLS, R.; McGLASSON, B.; GRAHAM, D.; JOYCE, D. Postharvest: an introduction to the physiology and handling of fruit, vegetables and ornamentals. New York: CAB International, 1998. $262 \mathrm{p}$.

ZAMPERLINI, G.P.; SANTOS, K.T.; BROETTO, S.G.; SILVA, D.M. Estudos preliminares do comportamento do papaya em diferentes etapas do processo entre a colheita e a mesa do consumidor. In: MARTINS, D. dos S. Papaya Brasil: manejo, qualidade e mercado do mamão.Vitória-ES: Incaper, 2007. 704p. 